\title{
Effect of low temperature on the regulation of cell volume after hypotonic shock in gastric cancer cells
}

\author{
ATSUSHI SHIOZAKI $^{1 *}$, YUZO YAMAZATO $^{1 *}$, TOSHIYUKI KOSUGA ${ }^{1}$, MICHIHIRO KUDOU $^{1}$, \\ KATSUTOSHI SHODA ${ }^{1}$, TOMOHIRO ARITA ${ }^{1}$, HIROTAKA KONISHI ${ }^{1}$, SHUHEI KOMATSU ${ }^{1}$, \\ TAKESHI KUBOTA ${ }^{1}$, HITOSHI FUJIWARA ${ }^{1}$, KAZUMA OKAMOTO ${ }^{1}$, \\ YOSHINORI MARUNAKA ${ }^{2-4}$ and EIGO OTSUJI ${ }^{1}$ \\ ${ }^{1}$ Division of Digestive Surgery, Department of Surgery and ${ }^{2}$ Department of Molecular Cell Physiology, \\ Graduate School of Medical Science, Kyoto Prefectural University of Medicine, Kyoto, Kyoto 602-8566; \\ ${ }^{3}$ Research Institute for Clinical Physiology, Kyoto Industrial Health Association, Kyoto, \\ Kyoto 604-8472; ${ }^{4}$ Research Center for Drug Discovery and Pharmaceutical Development Science, \\ Research Organization of Science and Technology, Ritsumeikan University, Kusatsu, Shiga 525-8577, Japan
}

Received February 25, 2019; Accepted June 20, 2019

DOI: $10.3892 /$ ijo.2019.4853

\begin{abstract}
Although peritoneal lavage with distilled water performed after surgery prevents peritoneal seeding, cancer cells may avoid rupture under mild hypotonicity through regulatory volume decrease (RVD), which is the homeostatic regulation of ion and water transport. The aim of the present study was to investigate the effect of low temperature on cell volume and cell death under hypoosmolal conditions and determine the underlying molecular mechanisms in gastric cancer (GC). Three human GC cell lines (NUGC4, KATO-III and MKN45) were exposed to hypotonic solutions, and the effects of low temperature on cell volume and viability were examined. Low temperature-induced changes in membrane transporters were evaluated, and knockdown and overexpression experiments were conducted to determine their effects on cell volume during hypotonic stimulation. Low temperature $\left(24^{\circ} \mathrm{C}\right)$ during hypotonic stimulation inhibited RVD and enhanced the cytocidal effects on GC cells. The expression of leucine-rich repeat containing protein $\mathrm{A}$ (LRRC8A), a component of a $\mathrm{Cl}$ channel, was decreased, and aquaporin 5 (AQP5) expression was increased at low temperatures. LRRC8A knockdown markedly slowed the decrease in cell volume following cell swelling by hypotonic shock. AQP5 overexpression enhanced initial cell swelling after hypotonic shock and increased
\end{abstract}

Correspondence to: Dr Atsushi Shiozaki, Division of Digestive Surgery, Department of Surgery, Kyoto Prefectural University of Medicine, 465 Kajii-cho, Kamigyo-ku, Kyoto, Kyoto 602-8566, Japan E-mail: shiozaki@koto.kpu-m.ac.jp

*Contributed equally

Key words: gastric cancer, peritoneal lavage, regulatory volume decrease, ion channel, aquaporin the final cell volume. These results suggest that a hypotonic solution at low temperature increased initial water influx via activation of AQP5 and decreased $\mathrm{Cl}^{-}$efflux via inhibition of LRRC8A. Therefore, low temperature enhanced the hypotonicity-induced cytocidal effects on GC cells, and these results may contribute to the development of a novel lavage method effective in reducing peritoneal recurrence in GC.

\section{Introduction}

Peritoneal dissemination is a common type of recurrence in patients with gastric cancer (GC) and is associated with a poor prognosis $(1,2)$. Several treatments, such as intraperitoneal chemotherapy, have been investigated, but their efficacy is limited $(3,4)$. Therefore, novel strategies for treating dissemination are needed to improve treatment outcomes. The regulation of extracellular osmolality may be a promising strategy, as hypotonic solutions exert cytocidal effects on cancer cells (5-9). Peritoneal lavage with distilled water (DW) has been performed after surgery for various types of cancers, as the hypotonic shock lyses free cancer cells and prevents peritoneal seeding.

In order to use the regulation of osmolality for cancer treatment, a thorough understanding of the physiological mechanisms of ion and water transport is crucial (5). Under conditions of mild hypoosmolality, regulatory volume decrease (RVD) occurs after hypotonicity-induced cell swelling. RVD results from the activation of ion channels and transporters, which in turn causes $\mathrm{K}^{+}, \mathrm{Cl}^{-}$and $\mathrm{H}_{2} \mathrm{O}$ efflux, leading to cell shrinkage $(10,11)$. The osmolality of the lavage water increases to mild hypotonicity due to intraperitoneal contamination from ruptured cells $(7,12)$. Under mild hypotonic conditions, tumor cells avoid rupture through RVD, which decreases the cytocidal effects of peritoneal lavage with DW.

To improve the efficacy of peritoneal lavage with DW, inhibition of RVD is necessary. We previously challenged 
cells with 5-nitro-2-(3-phenylpropylamino) benzoic acid (NPPB), a $\mathrm{Cl}^{-}$channel blocker, to increase cell volume by inhibiting RVD, and found that NPPB enhanced the cytocidal effects of hypotonic shock on various cancer cells, including GC cells (12-16). However, NPPB, which blocks multiple types of chloride channels, is neurotoxic in vivo; therefore, there is a need for development of a more specific, safe and simple method to inhibit RVD.

It was recently demonstrated that heat shock decreases the expression of the water channel aquaporin 5 (AQP5) on cell membranes by activating autophagic degradation (17). These findings indicate that temperature may regulate the expression of ion and/or water transporters on cell membranes, thereby affecting cell volume under hypotonic shock. Therefore, the aim of the present study was to investigate the effect of temperature on cell volume and cell death under conditions of hypoosmolality, and elucidate the underlying molecular mechanisms, in order to determine whether low temperature can enhance the cytocidal effect of hypotonic solutions in GC.

\section{Materials and methods}

Cell culture and materials. The human GC cell lines NUGC4, MKN45 and KATO-III were obtained from the RIKEN Cell Bank. Cells were grown in RPMI-1640 medium (Nacalai Tesque) supplemented with $100 \mathrm{U} / \mathrm{ml}$ penicillin, $100 \mu \mathrm{g} / \mathrm{ml}$ streptomycin and $10 \%$ fetal bovine serum. The cells were cultured in flasks or dishes in a humidified incubator at $37^{\circ} \mathrm{C}$ under $5 \% \mathrm{CO}_{2}$ in air.

Mouse monoclonal anti-LRRC8A (1:1,000 for western blotting; ab157489), cystic fibrosis transmembrane conductance regulator (CFTR) (1:1,000 for western blotting; ab2789, rabbit monoclonal anti-AQP5 (1:1,000 for western blotting; ab92328), and $\mathrm{Na}^{+} / \mathrm{K}^{+}$-ATPase antibodies (1:20,000 for western blotting; ab76020) were purchased from Abcam. Mouse monoclonal anti-AQP1 antibody (1:1,000 for western blotting; sc-32737) was obtained from Santa Cruz Biotechnology, Inc. Mouse monoclonal $\beta$-actin (ACTB) antibody (1:2,000 for western blotting; A5441) was purchased from Sigma Aldrich; Merck KGaA. Horseradish peroxidase (HRP)-conjugated anti-rabbit $(7074 \mathrm{~S})$ or mouse $(7076 \mathrm{~S})$ secondary antibodies (1:2,000 for western blotting) were purchased from Cell Signaling Technology, Inc.

$\mathrm{NaCl}$ isotonic and hypotonic solutions. A $140 \mathrm{mM} \mathrm{NaCl}$ isotonic solution, containing $140 \mathrm{mM} \mathrm{NaCl}, 5.0 \mathrm{mM} \mathrm{KCl}$, $1.0 \mathrm{mM} \mathrm{CaCl}_{2}, 1.0 \mathrm{mM} \mathrm{MgCl}_{2}, 5.0 \mathrm{mM}$ glucose and $10 \mathrm{mM}$ HEPES, was prepared. The $\mathrm{pH}$ of each solution was adjusted to 7.4 with $\mathrm{NaOH}$. Autoclaved Milli-Q water was used for our DW working solution. To analyze changes in the volume of cells subjected to hypotonic shock, hypotonic $1 / 4 \mathrm{NaCl}$ solution was prepared by diluting stock $\mathrm{NaCl}$ solution 4-fold with DW.

Measurement of cell volume changes in GC cells after hypotonic shock using a high-resolution flow cytometer. Cell volume measurements were performed using a high-resolution flow cytometer (Cell Lab Quanta; Beckman Coulter, Inc.), as previously described (12-16). This flow cytometer was designed to measure the electronic volume (EV) of a cell, and EV data of $>10,000$ cells were collected and analyzed using Quanta control software (Beckman Coulter, Inc.). GC cells grown in culture flasks were detached using trypsin-EDTA and centrifuged at $180 \mathrm{xg}$ at room temperature for $3 \mathrm{~min}$. A total of $1.0 \times 10^{6}$ pelleted cells were then suspended in $1 \mathrm{ml}$ of hypotonic $\mathrm{NaCl}$ solution at various temperatures to induce hypotonic shock. The suspended solution was subsequently displaced into a Vi-CELLTM Sample Cup (Beckman Coulter, Inc.) and cell volume was measured at 1, 5, 10, 20 and $30 \mathrm{~min}$ after exposure to each solution. The cell suspension in the isotonic $\mathrm{NaCl}$ solution was used as a control sample without hypotonic shock (0 $\mathrm{min})$.

Re-incubation of GC cells after exposure to DW. GC cells grown in culture flasks were detached using trypsin-EDTA and centrifuged at $180 \mathrm{x} \mathrm{g}$ at room temperature for $3 \mathrm{~min}$. A total of $2.0 \times 10^{5}$ pelleted GC cells were then suspended in DW and incubated for $1 \mathrm{~min}$ at $37^{\circ} \mathrm{C}$ or $24^{\circ} \mathrm{C}$. Subsequently, the suspension was centrifuged at $180 \mathrm{x} \mathrm{g}$ at room temperature for $3 \mathrm{~min}$, and the pelleted cells were re-suspended in culture medium and seeded on Costar 6-well plates (Corning Inc.). Approximately 48-72 $\mathrm{h}$ after plating, the cells were detached from the plates in trypsin-EDTA solution, and a viable cell count was performed using Trypan blue and the Countess Automated Cell Counter (Invitrogen; Thermo Fisher Scientific, Inc.).

DW was used for the re-incubation experiment, as severe hypotonicity was required to analyze the cytocidal effects. On the other hand, mild hypotonicity was used for RVD analysis, as RVD is a physiological phenomenon observed only in viable cells. Different conditions were set up according to the purpose of the experiments, such as functional and survival analyses.

Protein isolation. Cells were lysed with M-PER lysis buffer supplemented with Halt protease and phosphatase inhibitor cocktail (Thermo Fisher Scientific, Inc.), sonicated, and centrifuged at $20,000 \mathrm{xg}$ at $4^{\circ} \mathrm{C}$ for $10 \mathrm{~min}$ to obtain supernatants, which contained total protein. The Pierce Cell Surface Protein Isolation Kit (Pierce; Thermo Fisher Scientific, Inc.) was used to isolate cell surface proteins according to the manufacturer's protocol.

Western blotting. Protein concentrations were measured using a Protein Assay Rapid kit (Wako Pure Chemical Industries, Ltd.). Cell lysates containing equal amounts of protein were separated by SDS-PAGE with 7.5 or $10 \%$ gels and then transferred onto PVDF membranes (Merck KGaA). The membranes were probed with the indicated antibodies, and proteins were detected by the ECL Plus Western Blotting Detection system (GE Healthcare). The primary ACTB antibody was used as a loading control for whole lysates (17). The primary $\mathrm{Na}^{+} / \mathrm{K}^{+}$-ATPase antibody and the primary E-cadherin antibody were used as a loading control for cell membrane proteins (17-20).

Immunofluorescence staining. NUGC4 cells were cultured on SPL 8-chamber cell culture slides (SPL Life Science) for $24 \mathrm{~h}$. To compare protein expression between 
cells under normal conditions and those under low temperature for immunofluorescence staining, the cells were incubated at $37^{\circ} \mathrm{C}$ or $24^{\circ} \mathrm{C}$ for $12 \mathrm{~h}$ in $5 \% \mathrm{CO}_{2}$. The cells were subsequently fixed with $4 \%$ paraformaldehyde at room temperature for $20 \mathrm{~min}$, permeabilized in $0.25 \%$ Triton X-100 in phosphate-buffered saline (PBS), and incubated in blocking buffer containing $1 \%$ bovine serum albumin. The cells were then incubated with anti-LRRC8A or anti-AQP5 antibody at room temperature for $1 \mathrm{~h}$. After three washes in PBS, the cells were incubated with Alexa Fluor 488-labeled goat anti-rabbit secondary antibodies at room temperature for $1 \mathrm{~h}$. After three washes in PBS, the cells were incubated with rhodamine phalloidin and 40,6-diamidino-2-phenylindole (DAPI) for $30 \mathrm{~min}$. The slides were then mounted using Vectashield Mounting Medium (Vector Laboratories, Inc.; Maravai LifeSciences). The distribution of LRRC8A and AQP5 proteins was examined under a BZ-X700 microscope (Keyence Corporation).

siRNA transfection. Cells were transfected with $12 \mathrm{nmol} / 1$ LRRC8A siRNA (Stealth RNAiTM siRNA, cat. no. HSS125512, Invitrogen; Thermo Fisher Scientific, Inc.) using the Lipofectamine RNAiMAX reagent (Invitrogen; Thermo Fisher Scientific, Inc.) according to the manufacturer's instructions. Medium containing siRNA was replaced with fresh medium after $24 \mathrm{~h}$. The control siRNA provided (Stealth RNAiTM siRNA Negative Control; Invitrogen; Thermo Fisher Scientific, Inc.) was used as a negative control.

Overexpression study. Control-HaloTagR plasmid (Promega Corporation, cat. no. G6591) and AQP5-HaloTagR plasmid were transfected into NUGC4 cells using FuGENE HD transfection reagent (Promega Corporation, cat. no. E2311) according to the manufacturer's instructions. Transfection of vector was confirmed by fluorescence microscopy for HaloTag ${ }^{\circledR}$ fusion protein stained with the tetramethylrhodamine-conjugated HaloTag ${ }^{\circledR}$ ligand (Promega Corporation, cat. no. G8252) according to the manufacturer's protocol. After passaging cells, AQP5-expressing cells were used to measure cell volume.

Reverse transcription-quantitative polymerase chain reaction (RT-qPCR) analysis. Total RNA was extracted using an RNeasy kit (Qiagen). mRNA expression was measured by qPCR (7300 Real-Time PCR system; Applied Biosystems; Thermo Fisher Scientific, Inc.) using TaqMan gene expression assays (Applied Biosystems; Thermo Fisher Scientific, Inc.) according to the manufacturer's instructions. The expression levels of LRRC8A (Hs01555916_m1) and AQP5 (Hs00387048_m1) were measured. The expression of each gene was normalized against the housekeeping gene ACTB (Hs01060665_g1; Applied Biosystems; Thermo Fisher Scientific, Inc.). Each assay was performed in triplicate.

Statistical analysis. Results are expressed as means \pm standard error of the mean. Statistical analyses were performed using Student's t-test. Differences were considered statistically significant when the P-value was $<0.05$. These analyses were performed using the statistical software JMP (version 10, SAS Institute, Inc.).

\section{Results}

Cell volume changes in GC cells after hypotonic shock at various temperatures. To analyze serial cell volume changes in GC cells after hypotonic shock at various temperatures, cell volume and cell counts were simultaneously assessed after exposure to $1 / 4 \mathrm{NaCl}$ solution using Cell Lab Quanta. The results for NUGC4, MKN45 and KATO-III cells before and after hypotonic shock at $37^{\circ} \mathrm{C}$ (normal temperature) or $24^{\circ} \mathrm{C}$ (low temperature) are shown in Fig. 1A. After exposure to the hypotonic buffers, the population shifted to the right, indicating cell swelling by water influx. During exposure to hypotonicity, the cell volume decreased gradually, returning to the initial volume despite the continued presence of extracellular hypotonicity, which suggests the occurrence of RVD. It was also confirmed that low temperature did not affect cell volume in isotonic $\mathrm{NaCl}$ solution (Fig. 1B).

To investigate whether temperature affects cell volume changes in GC cells after hypotonic shock, mean cell volumes were measured following exposure to hypotonic $\mathrm{NaCl}$ solution at $37^{\circ} \mathrm{C}$ or $24^{\circ} \mathrm{C}$ using Cell Lab Quanta. Serial changes in the mean volume of GC cells following their exposure to hypotonic solutions at normal or low temperature are shown in Fig. 2A. The volume of GC cells treated with hypotonic solution at normal temperature initially increased for $1 \mathrm{~min}$, and subsequently decreased from $5 \mathrm{~min}$ after the start of treatment onwards, indicating RVD. By contrast, low temperature enhanced initial cell swelling and markedly slowed the decrease in cell volume following cell swelling induced by hypotonic shock in NUGC4, MKN45 and KATO-III cells. The results under low temperature suggested that these effects were induced by an increase in initial water influx and inhibition of RVD. On the other hand, high temperature $\left(42^{\circ} \mathrm{C}\right)$ did not significantly affect cell volume after hypotonic shock in GC cells (Fig. 2B).

To confirm the effect of low temperature on the cytocidal effects of hypotonic shock induced by DW on GC cells, suspended GC cell lines were re-incubated following exposure to DW at $37^{\circ} \mathrm{C}$ or $24^{\circ} \mathrm{C}$, and cultured cell number was counted 48-72 h later. As shown in Fig. 2C, the number of surviving cells after severe hypotonic shock at $24^{\circ} \mathrm{C}$ was lower compared with that at $37^{\circ} \mathrm{C}$, suggesting that low temperature enhanced the cytocidal effects of hypotonic shock.

Effect of low temperature on the expression of membrane transporters in GC cells. To examine the mechanism by which low temperature affects cell volume change after hypotonic shock, key membrane transporters, such as $\mathrm{Cl}^{-}$channels and water channels, that are the major cell volume regulators in hypotonicity, were investigated. Two $\mathrm{Cl}^{-}$channels (CFTR and LRRC8A) and two water channels (AQP1 and AQP5) were analyzed. The cell surface proteins of cells incubated at $37^{\circ} \mathrm{C}$ or $24^{\circ} \mathrm{C}$ for $12 \mathrm{~h}$ were isolated, and western blotting of cellular membrane proteins was performed. $\mathrm{Na}^{+} / \mathrm{K}^{+}$-ATPase and E-cadherin were examined as loading controls in the cell membrane. The expression of LRRC8A in the cell membrane fraction of cells incubated at low temperature was lower compared with that in cells at normal temperature (Fig. 3A). By contrast, the expression of AQP5 in the cell membrane was higher at low temperature (Fig. 3A). The expression levels of CFTR and AQP1 in 


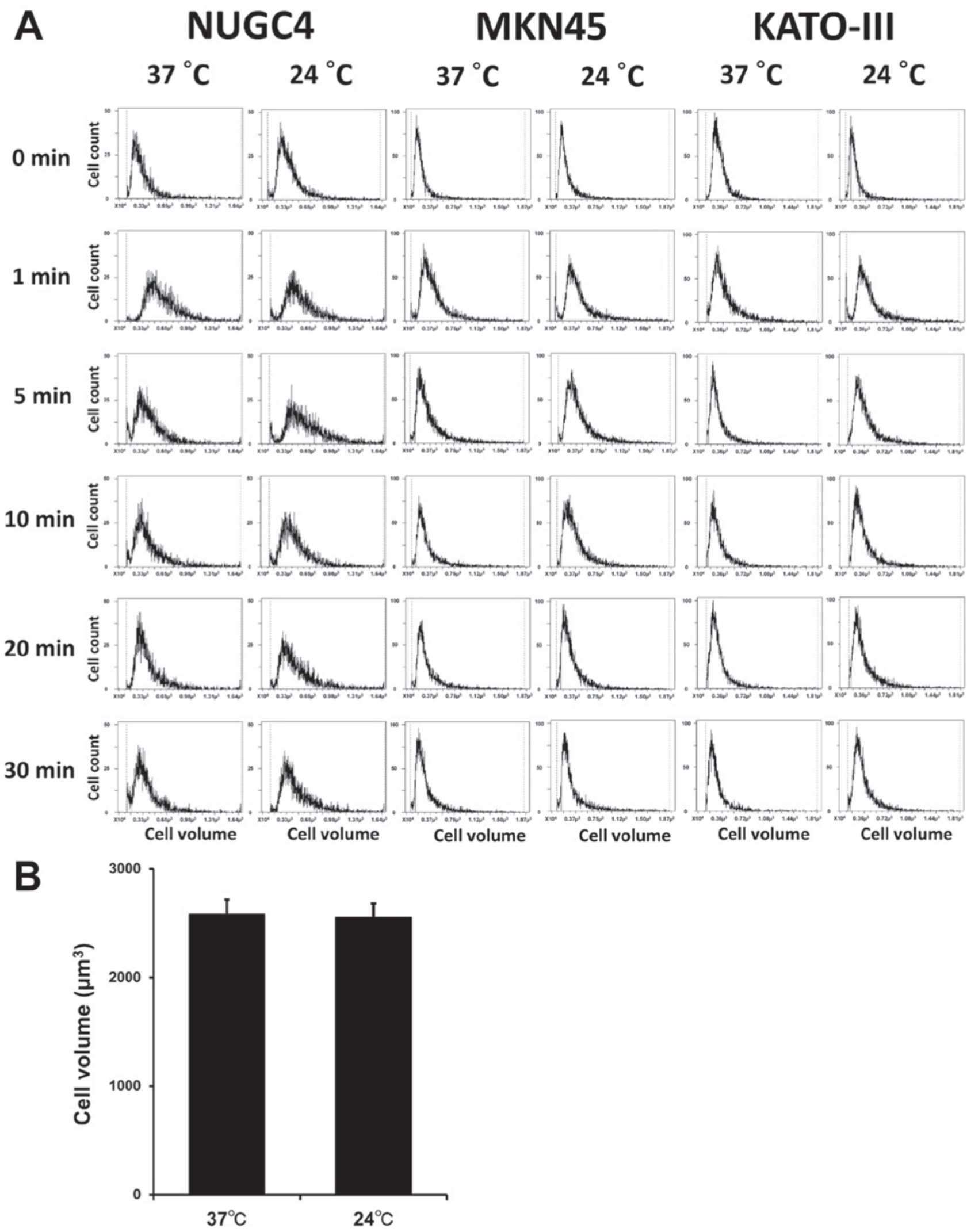

Figure 1. (A) Cell volume changes in gastric cancer (GC) cell populations after hypotonic shock. Cell volumes and cell counts of NUGC4, MKN45 and KATO-III cells were simultaneously assessed at1, 5, 10,20 and $30 \mathrm{~min}$ after hypotonic shock at $37^{\circ} \mathrm{C}$ or $24^{\circ} \mathrm{C}$ using the high-resolution Cel Lab Quanta flow cytometer. Isotonic $\mathrm{NaCl}$ solution was diluted 4-fold with distilled water. A cell suspension in isotonic $\mathrm{NaCl}$ solution was used as a control (0 min). (B) In the isotonic $\mathrm{NaCl}$ solution, low temperature did not affect the volume of GC cells. NUGC4 cells were exposure to isotonic $\mathrm{NaCl}$ solution for $20 \mathrm{~min}$ at $37^{\circ} \mathrm{C}$ or $24^{\circ} \mathrm{C}$. The results are presented as the mean \pm standard error of the mean $(n=3)$.

the cell membrane did not differ between high and low temperatures.
The expression and distribution of LRRC8A and AQP5 in NUGC4 cells treated at low temperature were examined using 
A
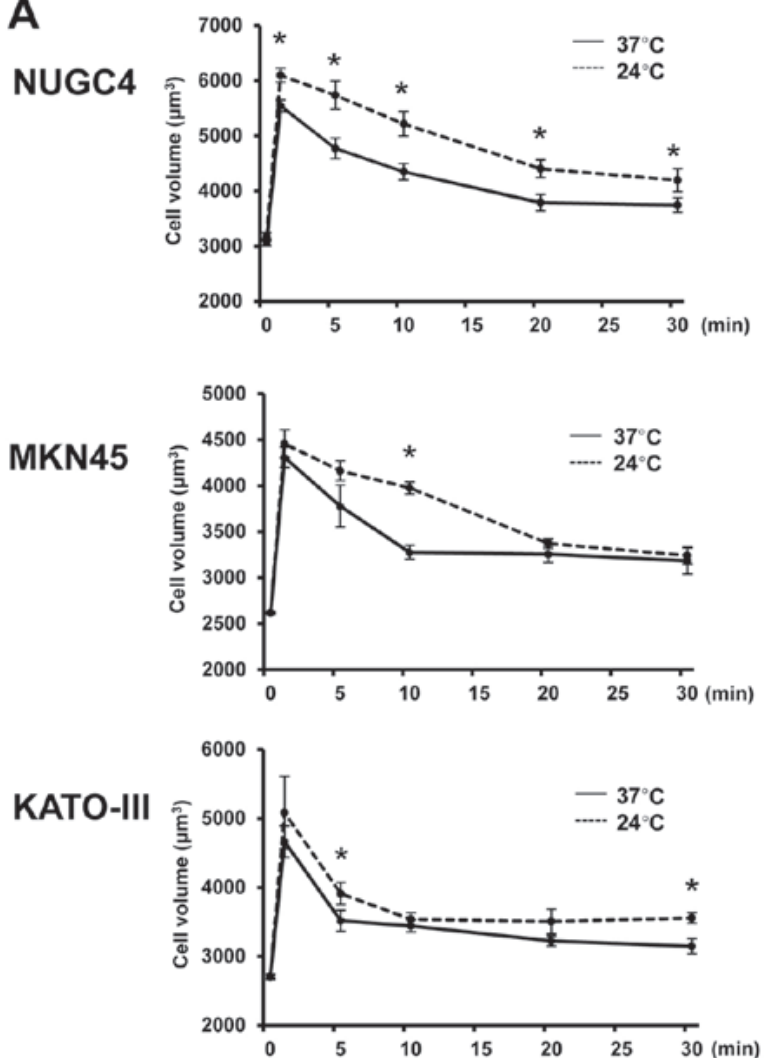

B

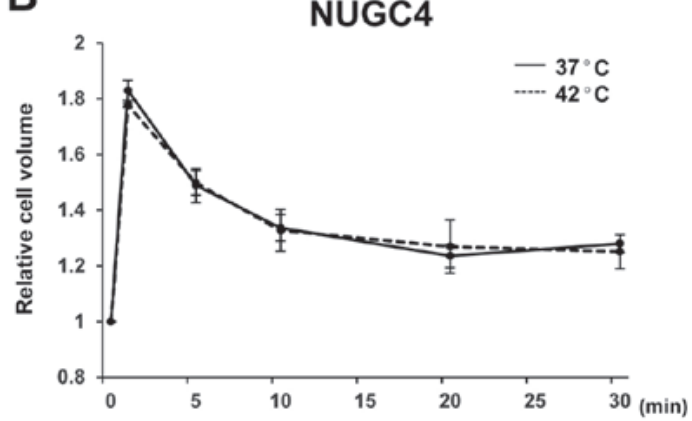

C

\section{NUGC4 MKN45 KATO-III}
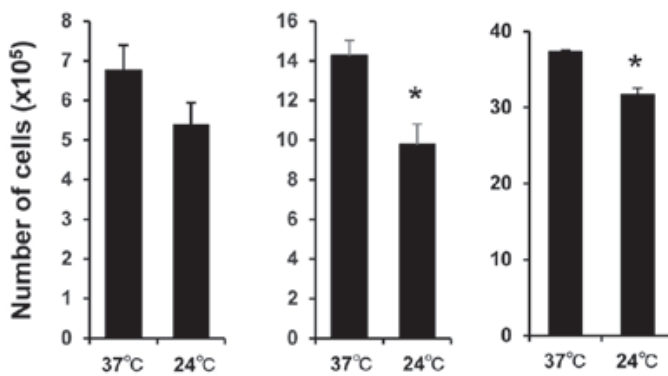

Figure 2. Effect of temperature on hypotonicity-induced cell volume changes and cytocidal effects in gastric cancer (GC) cells. (A) Cell volume was measured at the indicated times after exposure to $1 / 4 \mathrm{NaCl}$ solution at $37^{\circ} \mathrm{C}$ or $24^{\circ} \mathrm{C}$. A cell suspension in isotonic $\mathrm{NaCl}$ solution was used as a sample without hypotonic shock $(0 \mathrm{~min})$. The results are presented as the mean \pm standard error of the mean $(\mathrm{SEM})(\mathrm{n}=3)$. ${ }^{*} \mathrm{P}<0.05$ indicates significant difference from the control at the same time point. (B) The volume of NUGC4 cells was measured at the indicated times after exposure to $1 / 4 \mathrm{NaCl}$ solution at $37^{\circ} \mathrm{C}$ or $42^{\circ} \mathrm{C}$. The results are presented as the mean \pm SEM ( $=3)$. (C) Re-incubation experiments on suspended $\mathrm{GC}$ cells after exposure to distilled water for 1 min at $37^{\circ} \mathrm{C}$ or $24^{\circ} \mathrm{C}$. The number of cultured cells at $48 \mathrm{~h}$ (NUGC4, MKN45) or $72 \mathrm{~h}$ (KATO-III) after exposure to distilled water was counted. The results are presented as the mean $\pm \operatorname{SEM}(n=3) .{ }^{*} \mathrm{P}<0.05$ indicates significant difference from $37^{\circ} \mathrm{C}$.

A

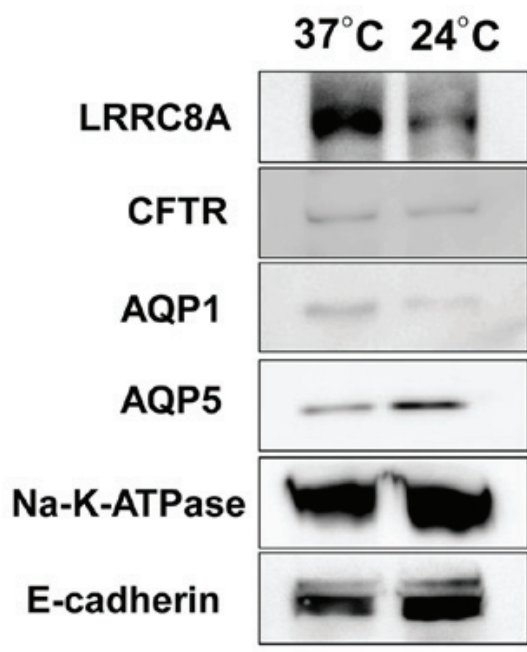

B

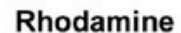

DAPI

LRRC8

Merged

$37^{\circ} \mathrm{C}$
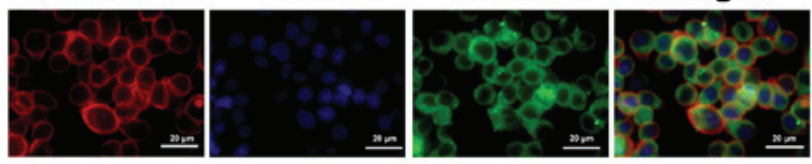

$24^{\circ} \mathrm{C}$
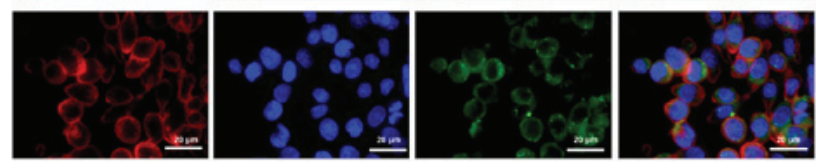

Rhodamine

DAPI
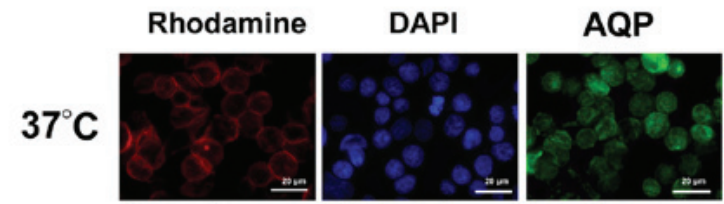

Merged

$24^{\circ} \mathrm{C}$
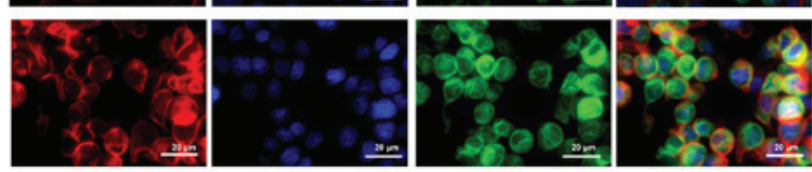

Figure 3. Effect of low temperature on the expression of membrane transporters in gastric cancer (GC) cells. (A) Western blotting of cellular membrane proteins to detect $\mathrm{Cl}^{-}$channels and water channels in NUGC4 cells incubated at $37^{\circ} \mathrm{C}$ or $24^{\circ} \mathrm{C}$ for $12 \mathrm{~h}$. LRRC8A expression in the cell membrane fraction of cells incubated at $24^{\circ} \mathrm{C}$ was lower compared with that in cells at $37^{\circ} \mathrm{C}$. AQP5 expression in the cell membrane was higher at low temperature. The cell surface proteins were isolated, and $\mathrm{Na}^{+} / \mathrm{K}^{+}$-ATPase and E-cadherin were examined as loading controls in the cell membrane. (B) The expression and distribution of LRRC8A and AQP5 in NUGC4 cells treated at low temperature was examined using immunofluorescence staining. Low temperature decreased LRRC8A expression and increased AQP5 expression in the membrane and cytoplasm of NUGC4 cells. AQP, aquaporin. 
A

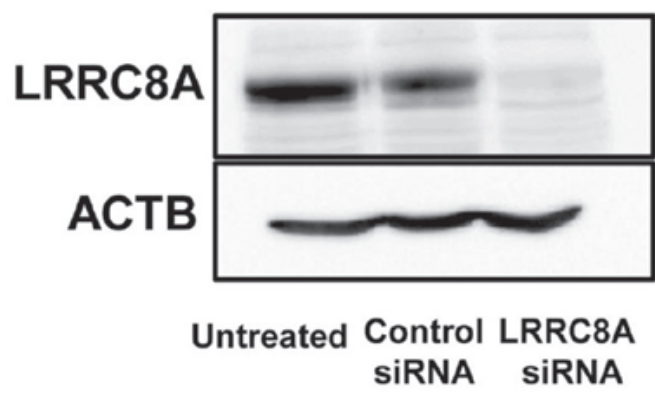

C

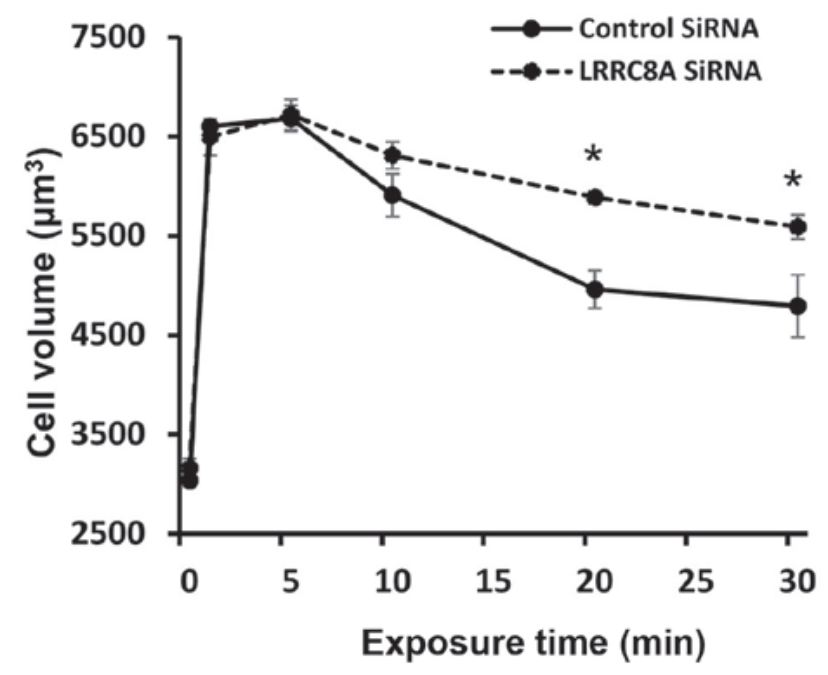

B $\begin{array}{ll}\text { Control } & \text { LRRC8A } \\ \text { SiRNA } & \text { SiRNA }\end{array}$

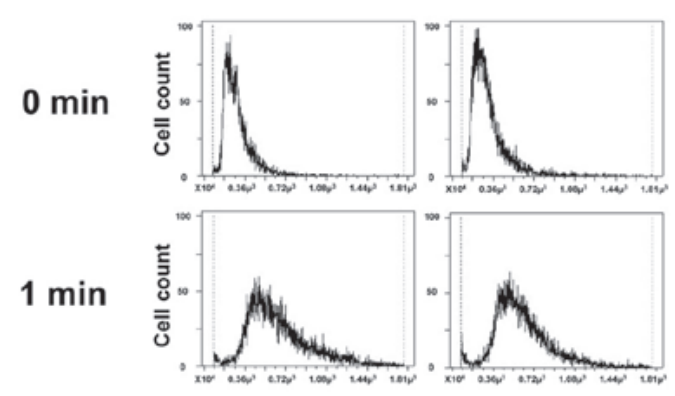

$5 \mathrm{~min}$
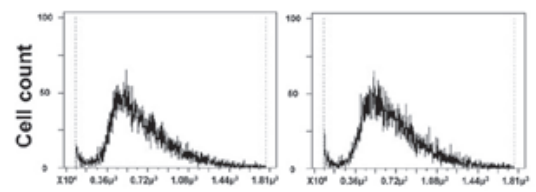

$10 \mathrm{~min}$
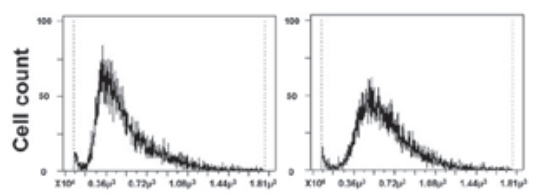

$20 \mathrm{~min}$
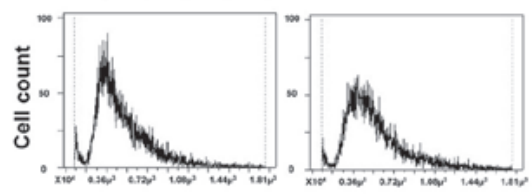

$30 \mathrm{~min}$

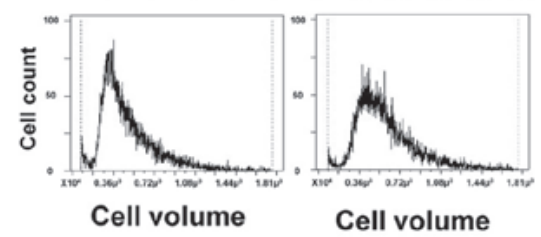

Figure 4. Effect of depletion of LRRC8A on hypotonicity-induced volume changes in gastric cancer (GC) cells. (A) LRRC8A siRNA effectively reduced LRRC8A protein levels in NUGC4 cells. The primary ACTB antibody was used as a loading control for whole-cell lysates. (B and C) Knockdown of LRRC8A markedly slowed the decrease in cell volume following cell swelling by hypotonic shock, which suggests that RVD was inhibited. The results are presented as the mean \pm standard error of the mean $(n=3)$. ${ }^{*} \mathrm{P}<0.05$, significantly different from the control at the same time point. RVD, regulatory volume decrease; ACTB, $\beta$-actin.

immunofluorescence. In order to identify their localizations more clearly, the cytoskeleton was labeled with rhodamine and the nucleus was labeled with DAPI. The staining intensity of LRRC8A in the cell membrane and cytoplasm of cells incubated at low temperature was lower compared with that in cells at normal temperature (Fig. 3B). By contrast, the expression of AQP5 in the cell membrane and cytoplasm was higher at low temperature (Fig. 3B). These results suggested that low temperature regulated the expression and distribution of the membrane transport proteins LRRC8A and AQP5.

Role of LRRC8A on hypotonicity-induced volume changes in $G C$ cells. Knockdown experiments using LRRC8A siRNA were conducted in NUGC4 cells to investigate the effects of LRRC8A depletion on volume change after hypotonic shock. LRRC8A siRNA effectively reduced LRRC8A protein levels in NUGC4 cells (Fig. 4A). The primary ACTB antibody was used as a loading control for whole lysates (Fig. 4A). The depletion of LRRC8A markedly slowed the decrease in cell volume following cell swelling by hypotonic shock (Fig. 4B and C), which suggests that this effect was induced by the inhibition of RVD. These results indicate that low temperature may suppress RVD after hypotonic shock via inhibition of LRRC8A expression.

Role of AQP5 on hypotonicity-induced volume changes in $G C$ cells. AQP5 was overexpressed in NUGC4 cells and the effects of AQP5 overexpression on cell volume change after hypotonic shock were investigated. Cells transfected with Control-HaloTag ${ }^{\circledR}$ plasmid and AQP5-HaloTag ${ }^{\circledR}$ plasmid were stained red (Fig. 5A), and AQP5 plasmid increased the AQP5 mRNA levels (Fig. 5B) and AQP5 protein levels plus HaloTag (Fig. 5C). The primary ACTB antibody was used as a loading control for whole lysates (Fig. 5C).

Cell volume changes after hypotonic shock were analyzed in GC cells transfected with Control-HaloTag ${ }^{\circledR}$ plasmid or AQP5-HaloTag ${ }^{\circledR}$ plasmid. AQP5 overexpression increased the initial cell swelling from $1 \mathrm{~min}$ after hypotonic shock and significantly increased the final cell volume (Fig. 5DE), suggesting that this effect was induced by an increased water influx. These results indicated that low temperature may increase water influx immediately after hypotonic shock via an increase in AQP5 expression. 
A

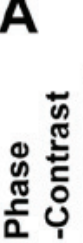

\section{Untreated}

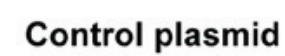

AQP5 plasmid
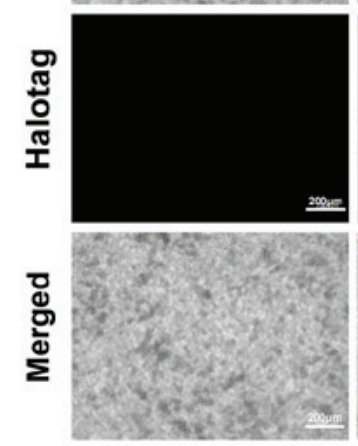

B

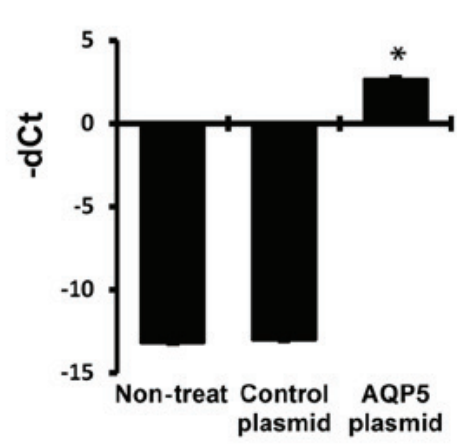

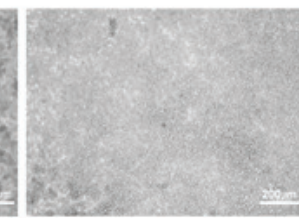
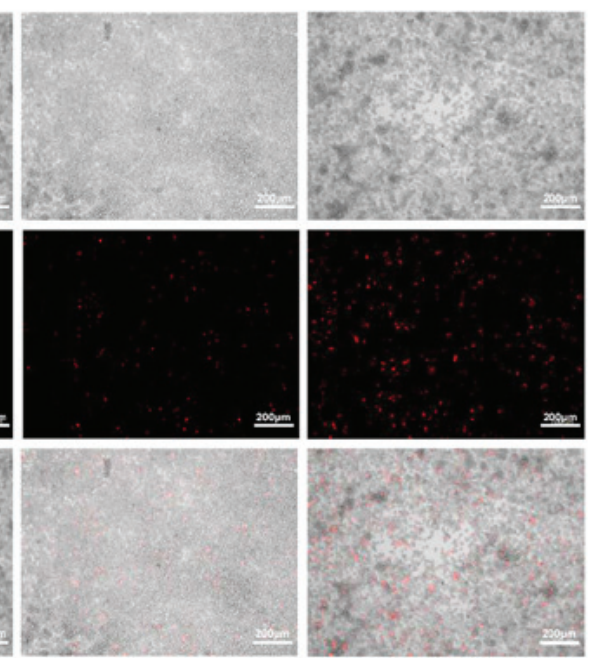

\section{D}

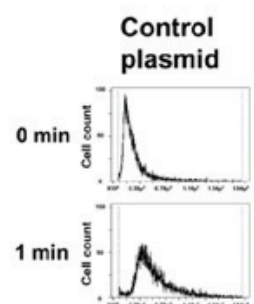

AQP5

plasmid
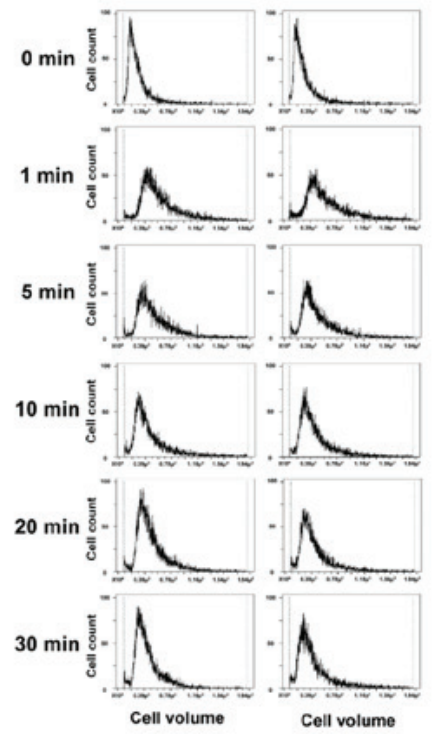

E

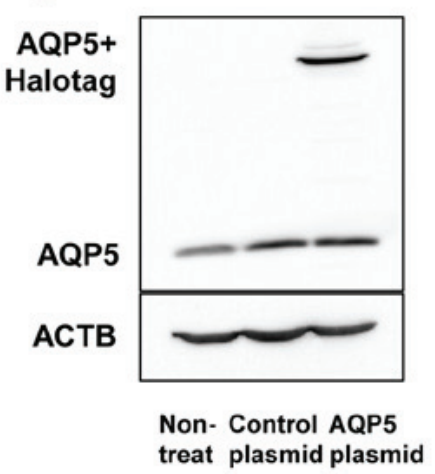

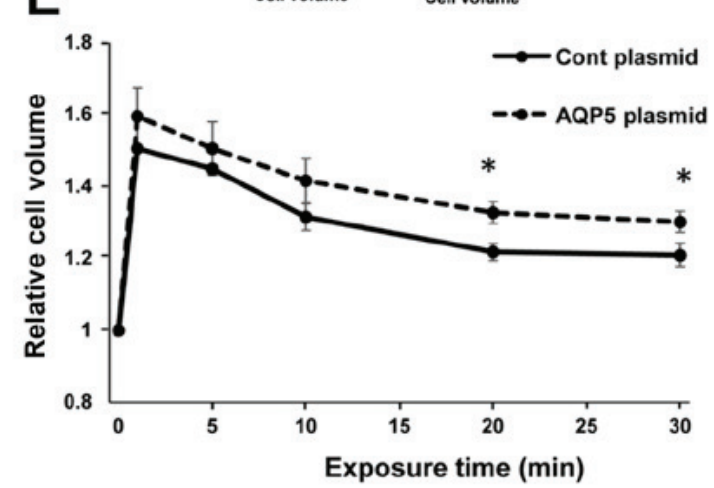

Figure 5. Effect of overexpression of AQP5 on hypotonicity-induced cell volume changes in gastric cancer (GC) cells. (A) Fluorescence microscopy for HaloTag ${ }^{\circledR}$ fusion protein. NUGC4 cells transfected with Control-HaloTag ${ }^{\circledR}$ plasmid and AQP5-HaloTag ${ }^{\circledR}$ plasmid are stained red. (B) AQP5 plasmid increased AQP5 mRNA levels in NUGC4 cells. The results are presented as the mean \pm standard error of the mean (SEM). $n=3$. "P $<0.05$, significantly different from control plasmid. (C) AQP5 plasmid increased the protein levels of AQP5 plus HaloTag in NUGC4 cells. The primary ACTB antibody was used as a loading control for whole-cell lysates. (D and E) Overexpression of AQP5 enhanced the initial cell swelling from 1 min after hypotonic shock and significantly increased final cell volume, which suggests increased water influx. The results are presented as the mean $\pm \mathrm{SEM}$. $\mathrm{n}=3$. " $\mathrm{P}<0.05$, significantly different from the control at the same time point. AQP, aquaporin; ACTB, $\beta$-actin.

These mechanisms are summarized in Fig. 6. Low temperature was shown to affect the expression and distribution of membrane transport proteins in GC cells. In particular, LRRC8A expression was decreased, and AQP5 expression was increased at low temperature. In the initial phase at low temperature, hypotonicity-induced cell swelling was enhanced by increased water influx via AQP5. In the next phase, low temperature blocked RVD by inhibiting $\mathrm{Cl}^{-}$efflux via LRRC8A, which suggests that low temperature enhanced the cytocidal effects of hypotonic solutions.

\section{Discussion}

Several in vitro and in vivo studies have investigated the cytocidal effects of hypotonic stress on cancer cells (6-9). We examined the changes in the morphology and volume of cancer cells subjected to hypotonic shock using several methods, such as a differential interference contrast microscope connected to a digital video camera, and revealed that DW exposure rapidly increases cell volume followed by cell rupture in esophageal, gastric, colonic, pancreatic and liver cancer cell lines (12-16). Our research group also determined the therapeutic effects of a peritoneal injection of DW into nude mice for the treatment of peritoneal dissemination of GC (21). Furthermore, several clinical studies have indicated that the use of DW lavage during surgery for cancer may delay tumor recurrence and improve survival, with minimal cost $(8,22-24)$. In addition, several clinical trials, including some for gastric cancer, have demonstrated the efficacy of the administration of hypotonic intraperitoneal cisplatin during surgery (25-27). Recently, Ohki et al reported that washing with DW during endoscopic examination reduces free GC cell exfoliation into the stomach lumen (28). The results of these studies clearly demonstrate the importance of osmolality in cancer treatments.

Even under hypotonic stress, cells can regulate their own volume after transient osmotic swelling by a mechanism referred to as RVD, which mainly occurs by $\mathrm{KCl}$ efflux induced by parallel activation of $\mathrm{K}^{+}$and $\mathrm{Cl}^{-}$channels $(10,11,29,30)$. In the present study, it was demonstrated that low temperature 


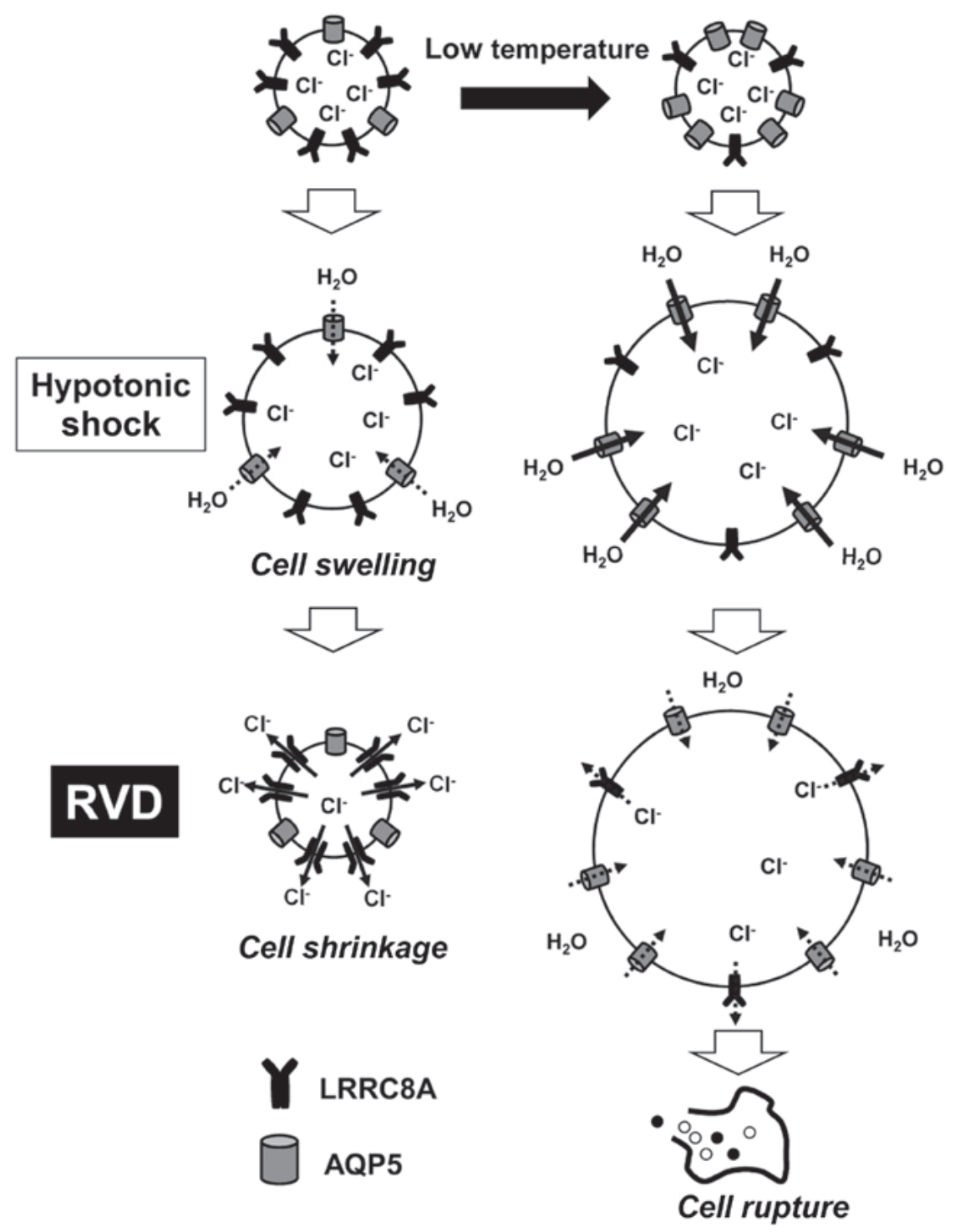

Figure 6. Molecular mechanism by which low temperature affects hypotonicity-induced volume changes in gastric cancer (GC) cells. Low temperature decreased LRRC8A expression and increased AQP5 expression in the membrane of GC cells. In the initial phase at low temperature, hypotonicity-induced cell swelling was enhanced by increased water influx via AQP5. Low temperature blocked RVD by inhibiting $\mathrm{Cl}^{-}$efflux via LRRC8A, which suggests that low temperature enhanced the cytocidal effects of the hypotonic solution. RVD, regulatory volume decrease. AQP, aquaporin; RVD, regulatory volume decrease.

inhibited RVD in GC cells. Similarly, Souza and Boyle reported that a decrease in temperature inhibited RVD in chick embryo cardiomyocytes (31). Although those studies demonstrated that calcium signaling is important, we herein focused on the regulatory mechanism via the expression of membrane transporters, such as $\mathrm{Cl}^{-}$channels and water channels. A particular type of $\mathrm{Cl}^{-}$channel, volume-regulated anion channel (VRAC) is involved in RVD. LRRC8A is a component of VRAC, and is essential for cell volume regulation (32). We observed that low temperature regulated RVD by decreasing the expression of LRRC8A in the cell membrane, and that depletion of LRRC8A with siRNA markedly slowed RVD in GC cells. A number of anion channel types associated with cell volume changes are classified into volume-activated anion channels (VAACs) and volume-correlated anion channels (VCACs) (33). VAACs can be directly activated by cell swelling, and include VRAC and the maxi-anion channel (Maxi-Cl) (33). Maxi-Cl is also directly involved in the RVD process by providing the volume-regulatory pathway for anion efflux or indirectly by releasing ATP (33). Although further investigations are required, it is suggested that other types of $\mathrm{Cl}^{-}$channels, such as Maxi- $\mathrm{Cl}$, may also involve the mechanism found in the present study.

AQPs are a family of transmembrane proteins that regulate transcellular water movement and play a role in cell volume regulation, and 13 of these subtypes are expressed in mammals (34-36). Mola et al demonstrated that AQP-mediated fast swelling kinetics trigger RVD using biophysical techniques to measure water flux through the plasma membrane of wild-type and AQP-knockout astrocytes and in an astrocyte cell line transfected with AQPs (37). They found that swelling in the presence of AQP is fast, whereas swelling in the absence of AQP is slow and depends on the composition of the lipid bilayer through which water influx occurs by simple diffusion. AQP5 overexpression was found to enhance initial cell swelling via increased water influx; we previously investigated heat shock-induced changes in AQP5 expression on cellular membranes and found that 
AQP5 expression was decreased via autophagic degradation in hepatocellular carcinoma cell lines (17). In addition, AQP5 knockdown and heat shock similarly decreased cell volume (17). However, we found completely opposite results investigating the effect of low temperature, which suggests that low temperature-induced overexpression of AQP5 may increase cell volume under hypotonic stress.

Ion channels play critical roles in various cancer cells, and physiological factors in cells represent novel targets for cancer therapy (38). Ion channels and transporters are important in GC cells (38-42), and $\mathrm{Cl}^{-}$transport is particularly important for the regulation of osmolality $(5,12,18,43)$. We previously investigated hypotonicity-induced cell volume changes by controlling RVD. In particular, we challenged GC cells with NPPB, a $\mathrm{Cl}^{-}$channel blocker, to increase cell volume by inhibiting RVD, and revealed that the cytocidal effects of a hypotonic solution were enhanced in GC cells (12). Furthermore, RVD was inhibited by quinine hydrochloride (Quin), which blocks $\mathrm{K}^{+}$channels. Treatment of GC cells with Quin enhanced the cytocidal effects of hypotonic shock by inhibiting RVD (43). The present study demonstrated that low temperature enhanced the cytocidal effects of hypotonic shock by inhibiting RVD. This novel and simple strategy for peritoneal lavage using low-temperature DW may overcome several problems, such as drug toxicity, at a low cost. Although the effects of peritoneal lavage with saline at low temperature have been investigated using an in vivo model (44), there are no reports on peritoneal hypothermia under hypotonic conditions. We consider that our findings, derived from a cell culture model, are also applicable in animal models, and further in vivo investigations may lead to the use of peritoneal hypotonic hypothermia as a prevention against peritoneal dissemination.

In summary, the present study demonstrated that low temperature during hypotonic stimulation inhibited RVD and enhanced the cytocidal effects on GC cells. The analysis of membrane transporters indicated that LRRC8A expression was decreased, whereas AQP5 expression was increased by stimulation with low temperature. Knockdown and overexpression experiments suggested that the effects of low temperature were induced by an initial increase of water influx via AQP5 and inhibition of $\mathrm{Cl}^{-}$efflux via LRRC8A. Further investigation of the physiological and molecular roles of low temperature under hypotonic conditions may uncover its potential as a novel lavage method to reduce peritoneal recurrence of GC following curative surgery.

\section{Acknowledgements}

Not applicable.

\section{Funding}

The present study was supported by Grants-in-Aid for Scientific Research (C) (17K10602, 17K10710, 18K08628, 18K08689) from the Japan Society for the Promotion of Science.

\section{Availability of data and materials}

All data generated or analyzed during the present study are included in this published article.

\section{Authors' contributions}

AS and YY designed the study, wrote the manuscript and performed the majority of the experiments; TK, MK, KS, TA, HK, SK, TK, HF and KO performed cellular physiological and molecular biological experiments; EO and YM were involved in editing the manuscript. All the authors have read and approved the final version of this manuscript for publication.

\section{Ethics approval and consent to participate}

Not applicable.

\section{Patient consent for publication}

Not applicable.

\section{Competing interests}

The authors declare that they have no competing interests.

\section{References}

1. Lim L, Michael M, Mann GB and Leong T: Adjuvant therapy in gastric cancer. J Clin Oncol 23: 6220-6232, 2005.

2. Rajdev L: Treatment options for surgically resectable gastric cancer. Curr Treat Options Oncol 11: 14-23, 2010.

3. Hartgrink HH, Jansen EP, van Grieken NC and van de Velde CJ: Gastric cancer. Lancet 374: 477-490, 2009.

4. Emoto S, Yamaguchi H, Kishikawa J, Yamashita H, Ishigami $H$ and Kitayama J: Antitumor effect and pharmacokinetics of intraperitoneal NK105, a nanomicellar paclitaxel formulation for peritoneal dissemination. Cancer Sci 103: 1304-1310, 2012.

5. Shiozaki A, Ichikawa D, Kosuga T, Marunaka Y and Otsuji E: Regulation of osmolality for cancer treatment. J Physiol Sci 67: 353-360, 2017.

6. Park KG, Chetty U, Scott W and Miller W: The activity of locally applied cytotoxics to breast cancer cells in vitro. Ann R Coll Surg Engl 73: 96-99, 1991.

7. Huguet EL and Keeling NJ: Distilled water peritoneal lavage after colorectal cancer surgery. Dis Colon Rectum 47: 2114-2119, 2004.

8. Zhou SJ, Zhang EL, Liang BY, Zhang ZY, Chen XP and Huang ZY: Distilled water lavage during surgery improves long-term outcomes of patients with ruptured hepatocellular carcinoma. J Gastrointest Surg 19: 1262-1270, 2015.

9. Fechner G, Pocha K, Schmidt D and Müller SC: Reducing recurrence and costs in superficial bladder cancer: Preclinical evaluation of osmotic cytolysis by distilled water vs. mitomycin. Int J Clin Pract 60: 1178-1180, 2006.

10. Caplanusi A, Kim KJ, Lariviere E, Van Driessche W and Jans D: Swelling-activated $\mathrm{K}^{+}$efflux and regulatory volume decrease efficiency in human bronchial epithelial cells. J Membr Biol 214: 33-41, 2006.

11. Miyazaki H, Shiozaki A, Niisato N and Marunaka Y: Physiological significance of hypotonicity-induced regulatory volume decrease: Reduction in intracellular $\mathrm{Cl}^{-}$concentration acting as an intracellular signaling. Am J Physiol Renal Physiol 292: F1411-F1417, 2007.

12. Iitaka D, Shiozaki A, Ichikawa D, Kosuga T, Komatsu S, Okamoto K, Fujiwara H, Ishii H, Nakahari T, Marunaka Y, et al: Blockade of chloride ion transport enhances the cytocidal effect of hypotonic solution in gastric cancer cells. J Surg Res 176: 524-534, 2012.

13. Kosuga T, Shiozaki A, Ichikawa D, Fujiwara H, Komatsu S, Iitaka D, Tsujiura M, Morimura R, Takeshita $H$, Nagata $H$, et al: Pleural lavage with distilled water during surgery for esophageal squamous cell carcinoma. Oncol Rep 26: 577-586, 2011.

14. Nako Y, Shiozaki A, Ichikawa D, Komatsu S, Konishi H, Iitaka D, Ishii H, Ikoma H, Kubota T, Fujiwara H, et al: Enhancement of the cytocidal effects of hypotonic solution using a chloride channel blocker in pancreatic cancer cells. Pancreatology 12: 440-448, 2012. 
15. Takemoto K, Shiozaki A, Ichikawa D, Komatsu S, Konishi H, Nako Y, Murayama Y, Kuriu Y, Nakanishi M, Fujiwara H, et al: Evaluation of the efficacy of peritoneal lavage with distilled water in colorectal cancer surgery: In vitro and in vivo study. J Gastroenterol 50: 287-297, 2015.

16. Kudou M, Shiozaki A, Kosuga T, Ichikawa D, Konishi H, Morimura R, Komatsu S, Ikoma H, Fujiwara H, Okamoto K, et al: Inhibition of regulatory volume decrease enhances the cytocidal effect of hypotonic shock in hepatocellular carcinoma. J Cancer 7: 1524-1533, 2016.

17. Kudou M, Shiozaki A, Kosuga T, Shimizu H, Ichikawa D, Konishi H, Morimura R, Komatsu S, Ikoma H, Fujiwara H, et al: Heat shock exerts anticancer effects on liver cancer via autophagic degradation of aquaporin 5. Int J Oncol 50: 1857-1867, 2017.

18. Bünger S, Roblick UJ and Habermann JK: Comparison of five commercial extraction kits for subsequent membrane protein profiling. Cytotechnology 61: 153-159, 2009.

19. Liu Y, Belkina NV, Park C, Nambiar R, Loughhead SM, Patino-Lopez G, Ben-Aissa K, Hao JJ, Kruhlak MJ, Qi H, et al: Constitutively active ezrin increases membrane tension, slows migration, and impedes endothelial transmigration of lymphocytes in vivo in mice. Blood 119: 445-453, 2012.

20. Kédinger V, Alpy F, Baguet A, Polette M, Stoll I, Chenard MP, Tomasetto C and Rio MC: Tumor necrosis factor receptor-associated factor 4 is a dynamic tight junction-related shuttle protein involved in epithelium homeostasis. PLoS One 3: e3518, 2008.

21. Shiozaki A, Ichikawa D, Takemoto K, Nako Y, Nakashima S, Shimizu H, Kitagawa M, Kosuga T, Konishi H, Komatsu S, et al: Efficacy of a hypotonic treatment for peritoneal dissemination from gastric cancer cells: An in vivo evaluation. BioMed Res Int 2014: 707089, 2014.

22. Whiteside OJ, Tytherleigh MG, Thrush S, Farouk R and Galland RB: Intra-operative peritoneal lavage--who does it and why? Ann R Coll Surg Engl 87: 255-258, 2005.

23. Lin $\mathrm{CH}$, Hsieh HF, Yu JC, Chen TW, Yu CY and Hsieh CB: Peritoneal lavage with distilled water during liver resection in patients with spontaneously ruptured hepatocellular carcinomas. J Surg Oncol 94: 255-256, 2006.

24. Chang YM,Hsu KF, Yu JC, Chan DC, Chen CJ,Chen TW,Hsieh CB and Hsieh HF: Distilled water peritoneal lavage in patients with rupture hepatocellular carcinoma. Hepatogastroenterology 60: 140-143, 2013.

25. Ichinose Y, Tsuchiya R, Koike T, Yasumitsu T, Nakamura K, Tada H, Yoshimura H, Mitsudomi T, Nakagawa K, Yokoi K, et al: A prematurely terminated phase III trial of intraoperative intrapleural hypotonic cisplatin treatment in patients with resected non-small cell lung cancer with positive pleural lavage cytology: The incidence of carcinomatous pleuritis after surgical intervention. J Thorac Cardiovasc Surg 123: 695-699, 2002

26. Tsujitani S, Fukuda K, Saito H, Kondo A, Ikeguchi M, Maeta M and Kaibara N: The administration of hypotonic intraperitoneal cisplatin during operation as a treatment for the peritoneal dissemination of gastric cancer. Surgery 131 (Suppl): S98-S104, 2002

27. Seto T, Ushijima S, Yamamoto H, Ito K, Araki J, Inoue Y, Semba $\mathrm{H}$ and Ichinose $\mathrm{Y}$; Thoracic Oncology Group: Intrapleural hypotonic cisplatin treatment for malignant pleural effusion in 80 patients with non-small-cell lung cancer: A multi-institutional phase II trial. Br J Cancer 95: 717-721, 2006.

28. Ohki A, Abe N, Yoshimoto E, Hashimoto Y, Takeuchi H, Nagao G, Masaki T, Mori T, Ohkura Y and Sugiyama M: Gastric washing by distilled water can reduce free gastric cancer cells exfoliated into the stomach lumen. Gastric Cancer 21: 998-1003, 2018.

29. McManus ML, Churchwell KB and Strange K: Regulation of cell volume in health and disease. N Engl J Med 333: 1260-1266, 1995.
30. Strange K, Emma F and Jackson PS: Cellular and molecular physiology of volume-sensitive anion channels. Am J Physiol 270: C711-C730, 1996.

31. Souza MM and Boyle RT: A moderate decrease in temperature inhibits the calcium signaling mechanism(s) of the regulatory volume decrease in chick embryo cardiomyocytes. Braz J Med Biol Res 34: 137-141, 2001.

32. Qiu Z, Dubin AE, Mathur J, Tu B, Reddy K, Miraglia LJ, Reinhardt J, Orth AP and Patapoutian A: SWELL1, a plasma membrane protein, is an essential component of volume-regulated anion channel. Cell 157: 447-458, 2014.

33. Okada Y, Okada T, Sato-Numata K, Islam MR, Ando-Akatsuka Y, Numata T, Kubo M, Shimizu T, Kurbannazarova RS, Marunaka Y, et al: Cell volume-activated and volume-correlated anion channels in mammalian cells: Their biophysical, molecular, and pharmacological properties. Pharmacol Rev 71: 49-88, 2019.

34. Ishibashi K, Hara S and Kondo S: Aquaporin water channels in mammals. Clin Exp Nephrol 13: 107-117, 2009.

35. Day RE, Kitchen P, Owen DS, Bland C, Marshall L, Conner AC, Bill RM and Conner MT: Human aquaporins: Regulators of transcellular water flow. Biochim Biophys Acta 1840: 1492-1506, 2014.

36. Hoffmann EK, Lambert IH and Pedersen SF: Physiology of cell volume regulation in vertebrates. Physiol Rev 89: 193-277, 2009.

37. Mola MG, Sparaneo A, Gargano CD, Spray DC, Svelto M, Frigeri A, Scemes E and Nicchia GP: The speed of swelling kinetics modulates cell volume regulation and calcium signaling in astrocytes: A different point of view on the role of aquaporins. Glia 64: 139-154, 2016.

38. Shiozaki A, Ichikawa D, Otsuji E and Marunaka Y: Cellular physiological approach for treatment of gastric cancer. World J Gastroenterol 20: 11560-11566, 2014.

39. Shiozaki A, Miyazaki H, Niisato N, Nakahari T, Iwasaki Y, Itoi $\mathrm{H}$, Ueda $\mathrm{Y}$, Yamagishi $\mathrm{H}$ and Marunaka Y: Furosemide, a blocker of $\mathrm{Na}^{+} / \mathrm{K}^{+} / 2 \mathrm{Cl}^{-}$cotransporter, diminishes proliferation of poorly differentiated human gastric cancer cells by affecting G0/G1 state. J Physiol Sci 56: 401-406, 2006.

40. Miyazaki H, Shiozaki A, Niisato N, Ohsawa R, Itoi H, Ueda Y, Otsuji E, Yamagishi H, Iwasaki Y, Nakano T, et al: Chloride ions control the G1/S cell-cycle checkpoint by regulating the expression of p21 through a p53-independent pathway in human gastric cancer cells. Biochem Biophys Res Commun 366: 506-512, 2008.

41. Shiozaki A, Otsuji E and Marunaka Y: Intracellular chloride regulates the $\mathrm{G}(1) / \mathrm{S}$ cell cycle progression in gastric cancer cells. World J Gastrointest Oncol 3: 119-122, 2011.

42. Shiozaki A, Ariyoshi Y, Iitaka D, Kosuga T, Shimizu H, Kudou M, Konishi T, Shoda K, Arita T, Konishi H, et al: Functional analysis and clinical significance of sodium iodide symporter expression in gastric cancer. Gastric Cancer 22: 473-485, 2019.

43. Kosuga T, Shiozaki A, Kudou M, Yamazato Y, Ichikawa D, Komatsu S, Konishi H, Okamoto K, Shoda K, Arita T, et al: Blockade of potassium ion transports enhances hypotonicity-induced cytocidal effects in gastric cancer. Oncotarget 8: 101394-101405, 2017.

44. Koca YS, Tarhan OR, Kaya S and Gökce Ceylan B: Effects of saline lavage temperature on peritoneal fibrinolysis and adhesion formation. Ulus Travma Acil Cerrahi Derg 22: 1-6, 2016. 